\title{
Structural Requirements for Parathyroid Hormone Action in Mature Bone \\ Effects on Release of Cyclic Adenosine Monophosphate and Bone Gamma-Carboxyglutamic Acid- containing Protein from Perfused Rat Hindquarters
}

\author{
Mona S. Calvo, Michael J. Fryer, Karen J. Laakso, Robert A. Nissenson, Paul A. Price, Timothy M. Murray, \\ and Hunter Heath III \\ Endocrine Research Unit, Division of Endocrinology and Metabolism, Department of Medicine, Mayo Clinic, Mayo Foundation, and \\ Mayo Medical School, Rochester, Minnesota 55905; Endocrine Unit, Veterans Administration Medical Center, San Francisco, California \\ 94121; Department of Biology, University of California, San Diego, California 92093; and Department of Medicine, \\ University of Toronto, Toronto, Ontario, Canada M5B 1 A6
}

\begin{abstract}
To determine the structural requirements for parathyroid hormone (PTH) activity in mature bone, we perfused the surgically isolated hindquarters of adult male rats with either native bovine PTH-(1-84) [bPTH-(1-84)] or the synthetic amino-terminal fragment, bovine PTH-(1-34) [bPTH-(1-34)]. Changes in the release of cyclic AMP (cAMP) and bone Gla protein (BGP) were monitored as evidence of bone-specific response to PTH; tissue specificity of the cAMP response was confirmed through in vitro examination of nonskeletal tissue response to PTH. Biologically active, monoiodinated ${ }^{125} \mathrm{I}-\mathrm{bPTH}-(1-84)$ was administered to determine if mature murine bone cleaves native hormone. We found that perfused rat bone continuously releases BGP, and that both bPTH-(1-84) and bPTH-(1-34) acutely suppress this release. In addition, both hormones stimulate cAMP release from perfused rat hindquarters. When examined on a molar basis, the magnitude of the cAMP response was dose-dependent and similar for both hormones, with doses yielding half-maximal cAMP responses. The response for bPTH-(1-34) was $0.5 \mathrm{nmol}$ and for bPTH-(1-84) was 0.7 nmol. Moreover, biologically active ${ }^{125} \mathrm{I}-$ bPTH-(1-84) was not metabolized in our hindquarter perfusion system. These findings indicate that PTH-(1-84) does not require extraskeletal or skeletal cleavage to an amino-terminal fragment in order to stimulate cAMP generation in, or suppress BGP release from, mature rat bone.
\end{abstract}

\section{Introduction}

Parsons and Robinson observed that perfusion of feline tibias with bovine parathyroid hormone (bPTH) ${ }^{1}$ stimulated calcium release from the bone only if the hormone had first been circulated through the whole animal (1). Their work led to the first suggestion that parathyroid hormone (PTH) requires extraskeletal processing to attain full potency in bone.

Later work showed intact 84-amino acid PTH [PTH-(1-84)] to be metabolized in liver and kidney to biologically inactive

Received for publication 8 April 1985 and in revised form 9 August 1985.

1. Abbreviations used in this paper: BGP, bone Gla protein, or osteocalcin; bPTH, bovine parathyroid hormone, $1,25(\mathrm{OH})_{2} \mathrm{D}_{3}, 1,25$ dihydroxyvitamin $\mathrm{D}_{3}$; HFBA, heptafluorobutyric acid; HPLC, high-performance liquid chromatography; IBMX, isobutylmethylxanthine; KHB, KrebsHenseleit bicarbonate buffer; NaOAC, sodium acetate; ODS-silica, octadecylsilyl silica; PTH, parathyroid hormone.

J. Clin. Invest.

(c) The American Society for Clinical Investigation, Inc.

0021-9738/85/12/2348/07 \$1.00

Volume 76, December 1985, 2348-2354 mid- and carboxyl (COOH)-terminal region fragments that enter the circulation (2). Under some circumstances, the hepatic processing may yield circulating biologically active amino-terminal ( $\mathrm{NH}_{2}$ )-fragments (3-5). Both $\mathrm{NH}_{2}$-fragments of PTH and the intact hormone are active in kidney, but information about structural requirements for PTH action in mammalian bone is contradictory. For example, Martin et al. (6) reported perfused canine tibias to selectively take up the amino-terminal fragment of bPTH [bPTH-(1-34)], but not bPTH-(1-84). Furthermore, only bPTH-(1-34) markedly stimulated release of cyclic AMP (cAMP) from the bones. Findings in other systems differ sharply from Martin's: bPTH-(1-84) is fully potent in activating adenyl cyclase in fetal rabbit calvarial membranes (7), isolated bone cells from rat calvarias (8), fetal rat calvarias (9), chick bone (10), and isolated chick bone cells (11). Bone may (9) or may not (6) metabolize PTH-(1-84), but there are no data to verify skeletal production of bioactive $\mathrm{NH}_{2}$-fragments of PTH. Age and species differences in the models used may partly explain the above discrepancies. In any event, the concept that PTH(1-84) requires extraskeletal cleavage to an $\mathrm{NH}_{2}$-terminal fragment for complete activity in bone is intriguing and possibly of great general importance.

Therefore, we have used the perfused rat hindquarters to test independently the hypothesis that bPTH-(1-34), but not bPTH(1-84), can stimulate skeletal release of cAMP. The model excluded the possibility of PTH metabolism by visceral organs, but maintained the bone intact in situ. We also tested the effects of PTH on skeletal release of bone Gla protein (BGP, or osteocalcin), as a separate assessment of PTH action on bone. Finally, the studies clearly demonstrated the utility of the perfused rat hindquarters as a system for studies of mature mammalian skeletal physiology.

\section{Methods}

Perfusion technique. The surgically isolated hindlimb technique used in these studies was modified from Bliziotes et al. (12) and Ruderman et al. (13). The system is shown schematically in Fig. 1. Male SpragueDawley rats (300-350 g, Holtzman Co., Madison, WI) were anesthetized with sodium pentabarbital $(5 \mathrm{mg} / 100 \mathrm{~g}$ body weight (body wt) i.p.). After making a midline ventral incision, we ligated major branches of the aorta and inferior vena cava (the renal, spermatic, and iliolumbar vessels, and inferior mesenteric artery). The epigastric and hypogastric branches of the iliac vessels were ligated to restrict flow to the viscera and body wall; ligatures were also placed around the distal colon, bladder neck, and vessels of the accessory sex organs. The colon was cut between two ligatures and the intestines removed. We next inserted a 22-gauge plastic catheter (Critikon, Tampa, FL) into the aorta anterior to the iliac bifurcation and immediately started the perfusion.

The aorta and vena cava were ligated above the arterial catheter and a bolus of heparin (100 U, Liquaemin sodium, Organon Diagnostics, West Orange, $\mathrm{NJ}$ ) in $2 \mathrm{ml}$ saline was delivered via the perfusate to ensure 
thorough flushing. The posterior vena cava was then quickly cannulated (18 gauge, Critikon) and the venous return collected. After removal of the kidneys, the perfused lower portion of the rat was surgically isolated from the forebody just above the renal arteries. The spinal stump was ligated with surgical steel and the preparation was transferred to a warmed, humidified plexiglass chamber. Finally, we inserted a temperature probe (Yellow Springs Instrument Co., Yellow Springs, $\mathrm{OH}$ ) into the rectal stump to monitor body temperature.

We continuously perfused the hindlimbs with oxygenated KrebsHenseleit bicarbonate buffer (KHB) containing fresh washed bovine red blood cells (hematocrit 30-35\%), 3\% bovine serum albumin (BSA) (Cohn Fraction V, Miles Laboratories, Kankakee, IL), and $10 \mathrm{mM}$ glucose, as described by Schultz et al. (14). The nonrecirculating perfusion system, shown in Fig. 1, used a peristaltic pump to deliver perfusate to a Silastic tubing lung (15) (0.058 in. i.d. and 0.077 in. o.d., Dow Corning, Midland, MI) at an average flow rate of $3 \mathrm{ml} / \mathrm{min}$. The tubing lung allowed oxygenation and achievement of physiologic $\mathrm{pH}$ (7.4) without foaming. $\mathrm{pH}$, $\mathrm{PO}_{2}$, and $\mathrm{PCO}_{2}$ were regulated by adjustment of gas mixture $\left(95 \% \mathrm{O}_{2} /\right.$ $5 \% \mathrm{CO}_{2}$ vs. $100 \% \mathrm{O}_{2}$ ). The oxygenated perfusate was warmed to $37^{\circ} \mathrm{C}$ by a condenser perfused with hot water (Lauda Div., Brinkmann Instruments Co., Westbury, NY). Perfusate then passed a mixing chamber with a hormone delivery portal, an arterial sampling portal, and a bubble trap proximal to the arterial cannula. Not shown in Fig. 1 is a line connected to a pressure transducer for monitoring changes in arterial line pressure. We saw no evidence of PTH-induced vasodilation in arterial pressure tracings or effluent flow rates.

The hindlimb preparation was flushed for $20 \mathrm{~min}$ (washout), after which four 5-min basal collections of effluent were made before hormone delivery. At the time of hormone or vehicle delivery (2- $\mathrm{ml}$ vol over 30 s), 101 -min collections were started, followed by four or more 5-min collections of venous effluent. At several points during each perfusion, arterial and effluent medium $\mathrm{pH}, \mathrm{PCO}_{2}$, and $\mathrm{PO}_{2}$ were measured (model 313 blood gas analyzer, Instrumentation Laboratory, Inc., Lexington, MA) as indicators of tissue viability. Degree of tissue perfusion was assessed at the end by introducing a vital dye into the perfusate and observing its distribution.

We collected all venous effluent samples on ice and removed the red blood cells by centrifugation. $0.5 \mathrm{ml}$ of the cell-free perfusate was mixed with an equal volume of $0.05 \mathrm{mM}$ sodium acetate $(\mathrm{NaOAc})$ buffer $(\mathrm{pH}$ 5.1) containing $0.5 \mathrm{mM}$ 3-isobutylmethylxanthine (IBMX) (Sigma Chemical Co., St. Louis, MO) and heated for $10 \mathrm{~min}$ at $90-95^{\circ} \mathrm{C}$. The denatured protein was removed by centrifugation at $3,000 \mathrm{~g}$ for $10 \mathrm{~min}$, and the supernatant frozen until assayed.

Assay for cAMP and BGP. Cell-free perfusate samples were assayed in triplicate for cAMP using the method of Steiner et al. (16-17), as modified by Wray et al. (18). We used a goat antiserum to cAMP (G-

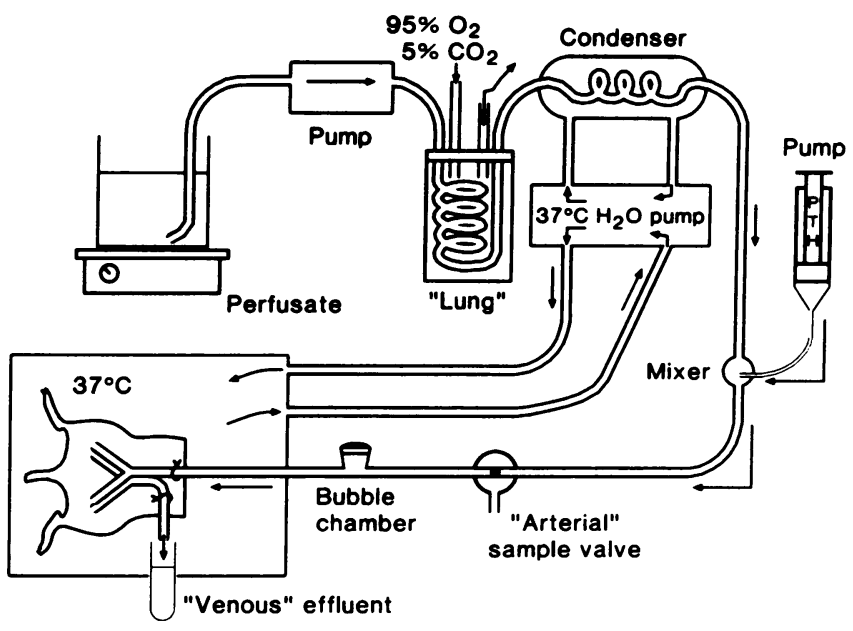

Figure 1. Schematic representation of the rat hindquarter perfusion system.
$829,1: 18,000$ final dilution) recently developed in our laboratory against 2-0' monosuccinyl cAMP. The assay was highly sensitive and specific for cAMP; no significant displacement of tracer ( ${ }^{125}$ I-cAMP) resulted when we added adenosine, ATP, ADP, AMP, guanosine, GDP, GMP, $2^{\prime} 3^{\prime}$ cGMP, uric acid, theophylline, inosine, 5'TTP, and 5'IDP. Any displacement of tracer by these analogs occurred at concentrations $>10^{-6}$ $M$ while $10^{-12}$ M $3^{\prime} 5^{\prime}$ cAMP effectively displaced the tracer. Without sample acetylation, the assay limit of detection was $0.25 \mathrm{pmol} / \mathrm{tube}$. All samples from a given rat were centrifuged for phase separation at the same time to minimize intraassay variation; interassay coefficient of variation was $13 \%$.

Hormone-stimulated release of cAMP from perfused rat hindlimb was calculated as follows: $\operatorname{cAMP}_{R}=\operatorname{cAMP}_{\mathrm{v}}[(1-\mathrm{hct} / 100)](\mathrm{F})(100 \mathrm{~g} /$ body $\mathrm{wt}$ ) where $\mathrm{CAMP}_{\mathrm{R}}$ is $\mathrm{cAMP}$ release $(\mathrm{pmol} / \mathrm{min}$ per $100 \mathrm{~g}$ hindlimb $w t$ ), CAMP $_{\mathrm{v}}$ is venous cAMP (picomoles per milliliter), hct is the perfusate hematocrit, $\mathrm{F}$ is the perfusate flow rate (milliliters per minute), and body wt is the weight of the hindlimbs (grams).

Samples of undiluted cell-free perfusate were frozen for radioimmunoassay of BGP content, as previously described by Price and Nishimoto (19).

Hormone preparations. In order to assure biological potency of all parathyroid hormone preparations used in our bone perfusion experiments, we assessed their biological activity with the guanyl nucleotideamplified canine renal plasma membrane adenylate cyclase assay of Nissenson et al. (20). The system included the GTP analog, 5'-guanylimidodiphosphate [Gpp(NH)p] $(100 \mu \mathrm{M})$, to augment adenylate cyclase sensitivity to PTH, and a phosphodiesterase inhibitor (1.0 mM IBMX). Synthetic bPTH-(1-34) was used as standard. This method produced consistent results in assays repeated over a year. We used bPTH-(1-84) generously provided by Dr. H. T. Keutmann, Massachusetts General Hospital, Boston, MA and synthetic bPTH-(1-34) (Beckman Instruments, Inc., Spinco Div., Palo Alto, CA). The biological activities of these hormones in the canine membrane assay (20) were 535 and $3,470 \mathrm{U} / \mathrm{mg}$, respectively; however, these values differ markedly from the manufacturer's potency estimates of 3,540 U/mg for bPTH-(1-84) (Dr. Keutmann, personal communication) and $6,800 \mathrm{U} / \mathrm{mg}$ for synthetic bPTH-(1-34). Inconsistency in the estimated biological activity of these hormones is probably attributable to differences in the bioassay procedures and conditions. To avoid confusion, and because no rational choice could be made among the bioassay values available, we chose to express the PTH dosages on a molar basis.

A range of molar doses of PTH was used to examine differences in potency of intact hormone and the synthetic fragment. At a given time, we simultaneously infused two hormone preparations in parallel perfusion systems. All hormone doses were combined in $2 \mathrm{ml}$ of KHB buffer containing 3\% BSA (vehicle); control perfusions were carried out with vehicle alone.

Hormone cleavage. Biologically active radioiodinated bPTH-(1-84) was prepared and purified as described by Rosenberg et al. (21) and Nissenson et al. (22). Our objective was to determine whether or not rat bone cleaves native PTH, potentially generating bioactive fragments. The bPTH-(1-84) is labeled with ${ }^{125}$ I on tyrosine-43 so that metabolism of this molecule to an $\mathrm{NH}_{2}$-terminal fragment would also yield a labeled $\mathrm{COOH}$-terminal fragment. Before iodination, the biological potency of the bPTH-(1-84) was estimated to be $2,650 \mathrm{U} / \mathrm{mg}$ using the rat renal membrane adenylate cyclase assay system (21). The specific activity of the preparation used in our studies was $0.012 \mathrm{mU} / 10^{6} \mathrm{dpm}$. Biological activity of the ${ }^{125} \mathrm{I}-\mathrm{bPTH}-(1-84)$ preparation was established before use by PTH receptor binding to rat osteosarcoma cells and chicken renal membranes (23); it was previously shown that the electrolytic iodination procedure does not decrease the biological potency of PTH (21).

The lyophilized labeled hormone was reconstituted with $0.01 \mathrm{M}$ acetic acid and aliquoted into doses containing $\sim 10^{6} \mathrm{cpm}$. Each dose was brought up to $2 \mathrm{ml}$ total volume with vehicle for injection into the hindlimb preparation. After delivery of the labeled hormone (over $30 \mathrm{~s}$ ), we made ten 3-min collections of venous effluent. Approximately $60 \%$ of the radioactivity of the injected dose was recovered in the first three venous collection tubes. The cell-free perfusate from these tubes was 
pooled $(\sim 15 \mathrm{ml})$ and extracted with octadecylsilyl-silica (ODS-silica), using Sep-Pak $\mathrm{C}_{18}$ cartridges (Waters Associates, Milford, MA) as previously described by Bennett et al. (24). The ODS-silica eluates were diluted 1:4 with $0.13 \%$ heptafluorobutyric acid (HFBA) and then chromatographed via reverse-phase high-performance liquid chromatography (HPLC) using a $\mu$ Bondapak $\mathrm{C}_{18}$ column (Waters Associates) equilibrated with $88 \%$ water and HFBA and $10 \%$ acetonitrile with HFBA (Waters Associates Automated Gradient Controller model 680 and two model 510 pumps). The sample was perfused with $88 \%$ water with HFBA and $12 \%$ acetonitrile with HFBA for 3-4 min to concentrate the sample at the column head. The column was eluted with a linear gradient of $28-$ $45 \%$ acetonitrile over $50 \mathrm{~min}$ at a flow rate of $1.5 \mathrm{ml} / \mathrm{min}$. This was increased to $48 \%$ acetonitrile over the next $30 \mathrm{~min}$ with no change in the flow rate and then held constant over the next $20 \mathrm{~min}$. Column fractions were collected every minute (model 1220, Isco Inc., Lincoln, $\mathrm{NE}$ ) in disposable glass test tubes and the radioactivity of each sample was quantified by direct gamma counting.

To verify that the HPLC method we used could detect fragments of PTH, we generated labeled cleavage products by incubating monoiodinated ${ }^{125}$ I-bPTH-(1-84) with purified bovine spleen cathepsin D (Sigma Chemical Co.). Cathepsin D has been identified as an enzyme involved in the generation of $\mathrm{COOH}$-terminal fragments of PTH in vitro (2526). The lyophilized enzyme was reconstituted with $0.05 \mathrm{M}$ ammonium acetate buffer, pH 5.0 and $300 \mu \mathrm{l}(1.5 \mathrm{U})$ was added to $300 \mu \mathrm{l}$ of ${ }^{125} \mathrm{I}-$ bPTH-(1-84) $\left(4 \times 10^{5} \mathrm{cpm}\right.$ total). The incubation mixture was vortexed and incubated for $15 \mathrm{~min}$ at $37^{\circ} \mathrm{C}$ and then brought up to $10 \mathrm{ml}$ total volume with cold vehicle, extracted on silica, and chromatographed as described above. Elution characteristics of bPTH-(1-84) and bPTH-(134) were determined by injecting the iodinated species with and without prior extraction on ODS-silica. The markers eluted at the same position independent of prior ODS-silica extraction. There was a $65 \%$ recovery of radioactivity after ODS-silica extraction and better than $90 \%$ recovery after HPLC.

Validation studies. Incubation of rat muscle with PTH has been reported by one group (27) to stimulate muscle cAMP accumulation, although another group found no effect (12). Vasodilatory actions of PTH and possible stimulation of vascular cAMP accumulation have also been reported (28-30). Since muscle and vascular tissue represent a significant amount of the perfused tissue in the hindlimb, it was necessary to show the specificity of the PTH responses.

Epitrochlearis muscles from the forelimbs of $150-\mathrm{g}$ male rats were rapidly dissected, cleaned, weighed, and placed intact in a $37^{\circ} \mathrm{C}$ oxygenated KHB buffer containing $0.5 \mathrm{mM}$ glucose, $5 \mathrm{mM}$ Hepes, $0.5 \mathrm{mM}$ IBMX, and $3 \mathrm{mg} / \mathrm{ml} \mathrm{BSA} \mathrm{(Cohn} \mathrm{fraction} \mathrm{V).} \mathrm{Before} \mathrm{incubation} \mathrm{of} \mathrm{the}$ muscle, bPTH-(1-34) $(5.6,2.8$, and $1.4 \mathrm{nmol} / \mathrm{ml})$, epinephrine $\left(10^{-6} \mathrm{M}\right)$, or vehicle $(0.01 \mathrm{mM}$ acetic acid) was added to the medium. The right and left epitrochlearis muscles were randomly assigned to hormonal treatments, incubated at $37^{\circ} \mathrm{C}\left(95 \% \mathrm{O}_{2}, 5 \% \mathrm{CO}_{2}\right.$ atmosphere $)$ in an oscillating water bath for $5 \mathrm{~min}$, then removed, blotted, and frozen in liquid nitrogen for later analyses. Incubation buffer from each muscle was mixed with an equal volume of $0.05 \mathrm{mM} \mathrm{NaOAC}$ buffer (pH 5.1), heated in a $90^{\circ} \mathrm{C}$ water bath for $10 \mathrm{~min}$, then cooled, and centrifuged. The supernatant was assayed for cAMP as described above, and the results expressed as picomoles cAMP released per gram muscle. We homogenized frozen muscle with a glass-on-glass tissue homogenizer in 1.5 $\mathrm{ml}$ of $0.05 \mathrm{mM} \mathrm{NaOAc}$ buffer (pH 5.1), containing $0.5 \mathrm{mM}$ IBMX. Tritiated cAMP (New England Nuclear, Boston, MA) was added to each muscle homogenate to quantitate recovery of the cyclic nucleotide $(>85 \%)$. The homogenate was heated in a $90^{\circ} \mathrm{C}$ bath for $10 \mathrm{~min}$, cooled, and the protein pellet separated by centrifugation. The supernatant cAMP content was assayed as described and the results expressed as picomoles cAMP per gram muscle.

We also examined the ability of PTH to stimulate cAMP release from rat hindlimb vessels. Sections of the external iliac arteries and veins from 350-g male rats were excised and freed of adherent connective tissue while immersed in $4^{\circ} \mathrm{C} \mathrm{KHB}$ buffer. The vessels were blotted, weighed, and incubated with bPTH-(1-34) $(2.8 \mathrm{nmol} / \mathrm{ml})$, prostaglandin $\mathrm{E}_{2}(10 \mathrm{ng} / \mathrm{ml})$, or PTH vehicle $(0.01 \mathrm{mM}$ acetic acid) for $5 \mathrm{~min}$. The incubation media were processed and analyzed as described for muscle, and the results reported as picomoles cAMP released per gram vascular tissue. In addition, we examined the ability of PTH to stimulate cAMP release from isolated murine adipocytes (31) and bone marrow cells (32).

Statistical analyses. Data are presented as mean \pm SEM, unless stated otherwise. Student's $t$ test was used to determine significance of differences between results of control and experimental tissue incubations. In experiments involving serial effluent sampling after hormone stimulation, the data were reduced to one response per rat by summation of all responses from the time of hormone delivery to $30 \mathrm{~min}$. Statistical significance of differences was assessed by analysis of variance. When significant differences were indicated, Student-Newman-Keul's test was used to determine which differences were significant.

\section{Results}

Viability and system specificity. Fig. 2 illustrates the ability of the model to maintain tissue uptake and exchange of oxygen for $80 \mathrm{~min}$; however, we have extended the perfusion beyond 120 min with good results. The arterial $\mathrm{pH}$ and $\mathrm{PO}_{2}$ showed little variation over the course of a perfusion. Maintenance of arterialvenous differences in $\mathrm{PO}_{2}$ indicated tissue viability, and were confirmed at the end of each perfusion.

We found that incubation of nonskeletal tissue with PTH had no effect on cAMP release or tissue content. Fig. 3 shows typical results from incubation of rat epitrochlearis muscles, wherein we found no stimulation by PTH of cAMP release to the medium or changes in muscle cAMP content. In all other tissues examined (external iliac vessels, bone marrow, and adipose tissue) PTH also failed to stimulate release of cAMP (data not shown).

The responses to increasing doses of bPTH-(1-34) and bPTH(1-84) are shown in Fig. 4. For both hormones, peak cAMP release occurred within $10 \mathrm{~min}$ of hormone delivery over a wide range of doses. cAMP concentrations in effluent were essentially back to pretreatment levels at 20-30 min. For both dose-response studies, we estimated the areas under individual response curves by summing the values of all time points. The reduced data, plotted against hormone dose, allowed a comparison of the

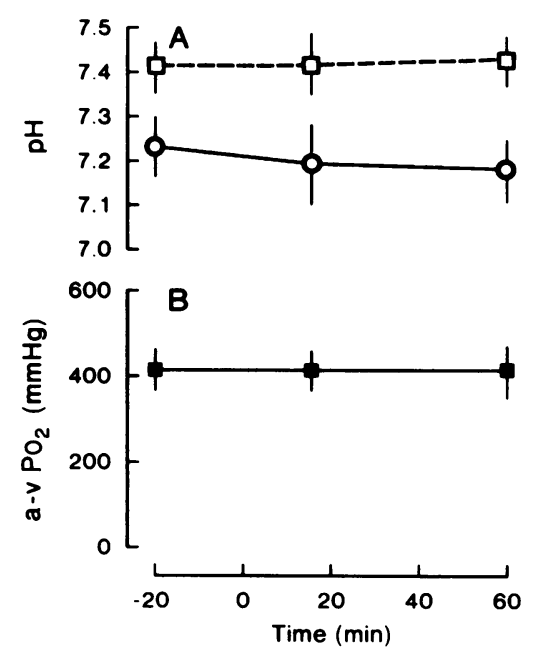

Figure 2. Mean perfusate $\mathrm{pH}$ and arterial-venous differences in $\mathrm{PO}_{2}$ monitored during a continuous 80 -min perfusion (mean $\pm 2 \mathrm{SD}, n$ $=24)$. ( $A$ ) Arterial $\mathrm{pH}$ (before rat perfusion) ( $\square$ ); venous $\mathrm{pH}$ (after perfusion of rat) (O). (B) Arterial-venous differences in $\mathrm{PO}_{2}$ ( $\mathrm{a}$, determined by subtraction of $\mathrm{PO}_{2}$ in venous effluent from the arterial value). 


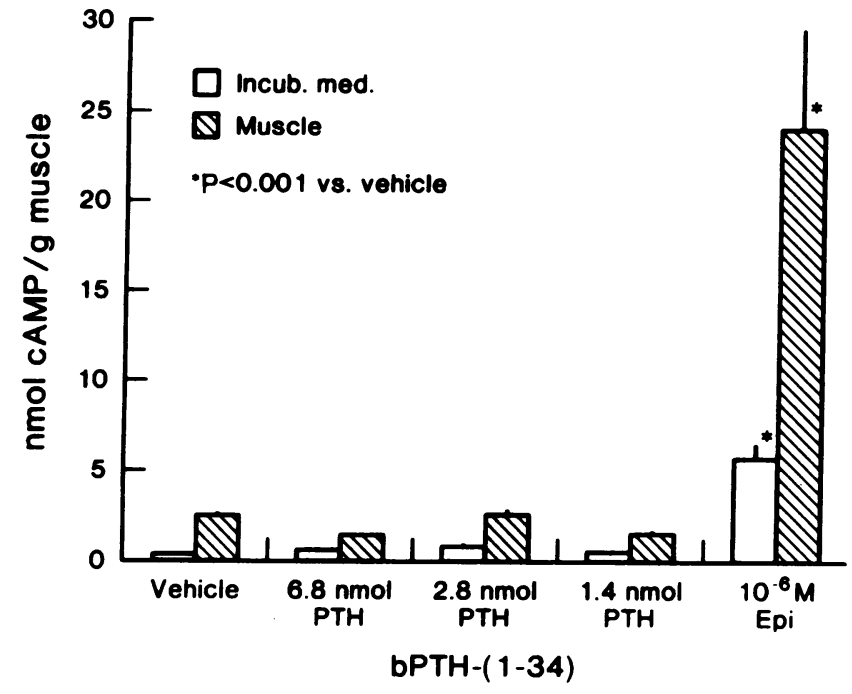

Figure 3. cAMP released from or contained in rat epitrochlearis muscle incubated with vehicle, bPTH-(1-34) $(6.8,2.8,1.4 \mathrm{nmol} / \mathrm{ml})$ or $10^{-6} \mathrm{M}$ epinephrine (EPI) ( $n=8$ for all treatments). Data are mean \pm SE. Student's $t$ test was used to assess differences between hormone treatment and control vehicle incubation $\left({ }^{*} P<0.001\right)$.

bioactivity of the two hormones (Fig. 5). Increasing the dose of PTH gave a biphasic cAMP response, with declining total cAMP release above $6.8 \mathrm{nmol} /$ preparation for $\mathrm{bPTH}-(1-84)$ and 11.6 $\mathrm{nmol} / \mathrm{preparation}$ for $\mathrm{bPTH}-(1-34)$. The concentrations of bPTH-(1-34) and bPTH-(1-84) required for half maximal release of cAMP were estimated to be 0.5 and $0.7 \mathrm{nmol}$, respectively.

The rat hindlimbs released immunoreactive BGP, with the release slowly declining over the 120 -min perfusion (Fig. 6). Treatment with bPTH-(1-84), $6.85 \mathrm{nmol}$, produced a significantly greater decrease of BGP release than in vehicle perfused hindquarters. Synthetic bPTH-(1-34), $2.78 \mathrm{nmol}$, also suppressed BGP release but to a lesser degree. The different magnitude of effects by the two peptides probably resulted from the nearly 2.5-fold difference in dose.

Metabolism of biologically active ${ }^{125} I-b P T H-(1-84)$. The fate of biologically active ${ }^{125} \mathrm{I}-\mathrm{bPTH}-(1-84)$ in our hindquarter per- fusion system is illustrated in Fig. 7. The profile shown represents the average of values from two rats perfused with similar doses of ${ }^{125} \mathrm{I}-\mathrm{bPTH}-(1-84)$. We carried out a total of four separate perfusions with this labeled hormone, all of which yielded the same results. Chromatography of pooled venous effluent containing the greatest radioactivity revealed one major peak which coeluted with intact bPTH-(1-84). The HPLC profiles of labeled bPTH-(1-84) were identical before and after perfusions through the rat hindquarters. Approximately $60 \%$ of the radioactive label infused was contained in the venous effluent collected within the first $12 \mathrm{~min}$. Subsequent collections were also pooled and chromatographed, but they contained no new peaks of activity.

Fig. 7 also illustrates the ability of our method (ODS-silica extraction followed by reverse-phase HPLC)to distinguish ${ }^{125} \mathrm{I}-$ bPTH-(1-84) from cleavage products generated enzymatically in vitro. From these results, we are confident that the ODS-silica extraction procedure did not cause loss of fragments possibly generated in the hindquarter perfusion.

\section{Discussion}

The present studies verify that PTH evokes rapid, dose-related increases of cAMP release from perfused rat hindquarters (12), and suggests that PTH acutely suppresses release of BGP. We believe that both responses reflect the actions of PTH on bone. There is no serious question about specificity of the BGP response, since BGP occurs only in skeletal tissue (33). On the other hand, adenylate cyclase occurs in many tissues; muscle (27) and fat cells (31), and fat cell ghosts (34) reportedly respond to PTH with increased cAMP generation. However, Bliziotes et al. (12) found no effect of bPTH-(1-34) on rat muscle cAMP content or release, and repeated trials in our laboratory also showed no effect. In addition, we found no effect of PTH on cAMP release from murine fat cells $(31,34)$, marrow cells $(32)$, and blood vessels. Despite the heterogeneity of perfused tissue in this system, we conclude that the BGP and cAMP responses were specific for bone.

Martin et al. (6) found only a weak cAMP response to bPTH(1-84) in perfused canine tibia, while bPTH-(1-34) markedly stimulated cAMP release. A major finding of the present study was that bPTH-(1-84) and bPTH-(1-34) were potent stimulators

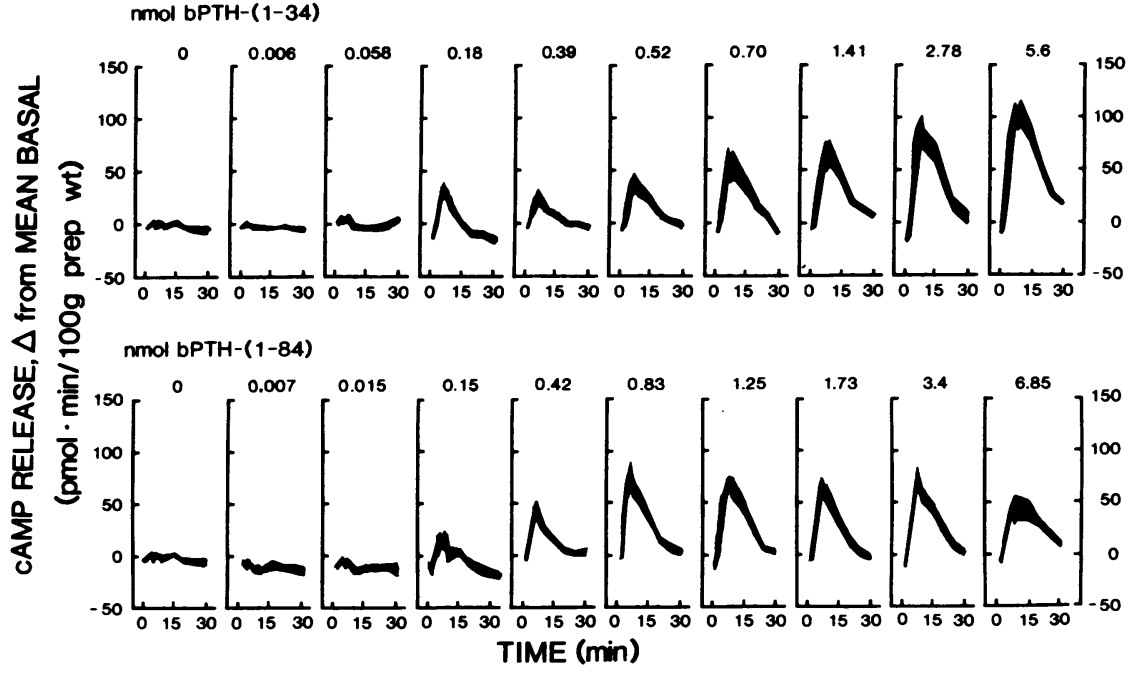

Figure 4. cAMP released from perfused rat hindquarters after stimulation with various doses of bPTH. Responses to increasing doses of bPTH-(1-34) ranging from 0 to $5.6 \mathrm{nmol}$ per preparation are shown in the upper panel. Responses to bPTH-(1-84) with a dose range of 0 to $6.8 \mathrm{nmol}$ per preparation are shown in the lower panel. Each individual curve represents group mean \pm SEM. Hormone doses were delivered in a $2-\mathrm{ml}$ bolus over $30 \mathrm{~s}$ at time 0 . Mean basal cAMP release was determined from five samples collected before hormone delivery. The change in cAMP release was determined by subtracting the mean basal value from each response. 


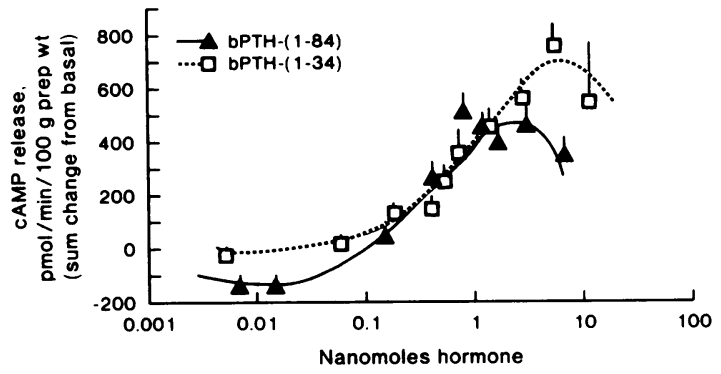

Figure 5. Dose response curve employing the sum change in cAMP

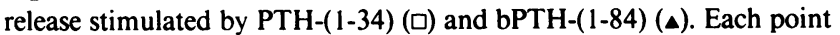
represents the group mean \pm SEM. The data in Fig. 4 showing PTH stimulation of cAMP release in the individual dose response curves were reduced to single data points by summing the numeric values of all points between 0 time and $30 \mathrm{~min}$.

of cAMP release from mature rat bone. For both hormones, the increase of cAMP release occurred within $3 \mathrm{~min}$ of hormone delivery and attained maximal values by 7-8 $\mathrm{min}$. The magnitude of response was dose-dependent for both hormones. These findings strongly suggest that intact PTH does not require extraskeletal cleavage to an amino-terminal fragment to stimulate adenylate cyclase in mature rat bone.

Other work supports our findings. For example, cultured rat bone cells $(8)$ and fetal rat calvarias $(9,35)$ are fully responsive to bPTH-(1-84). Rat calvarias may be able to cleave PTH (9), but there is no evidence for skeletal production of bioactive PTH fragments. Furthermore, fetal rabbit calvarial membranes responded to bPTH-(1-84) without apparent ability to metabolize the hormone (7). Our data clearly demonstrated that perfused murine bone did not cleave intact bPTH-(1-84) during a single pass. In addition, chromatography of effluent collected later than 12 min after hormone delivery revealed no new peaks, indicating that any delay in the release of the hormone was not due to skeletal cleavage. These findings further suggest that native PTH requires no metabolic activation for full potency in adult rat bone.

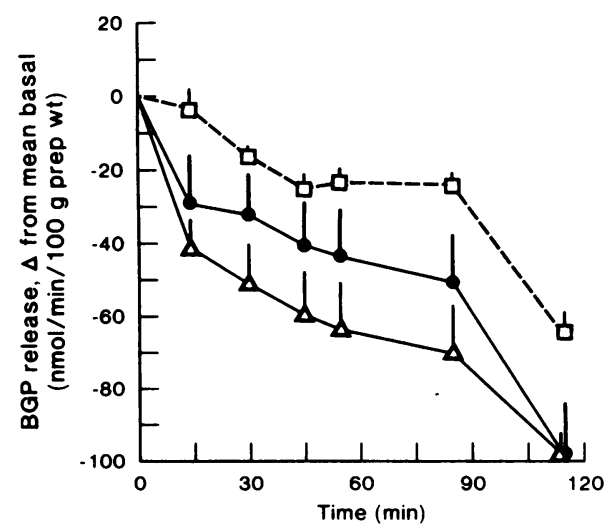

Figure 6. Changes in release of BGP from perfused rat hindquarters after a bolus infusion of vehicle (ㅁ), $2.78 \mathrm{nmol}$ of bPTH-(1-34) (๑), or $6.85 \mathrm{nmol}$ of bPTH-(1-84) $(\Delta)$. Group mean $\pm \operatorname{SEM}(n=8)$ were calculated by subtraction of mean basal value of BGP release determined from five consecutive collections made before hormone infusion.

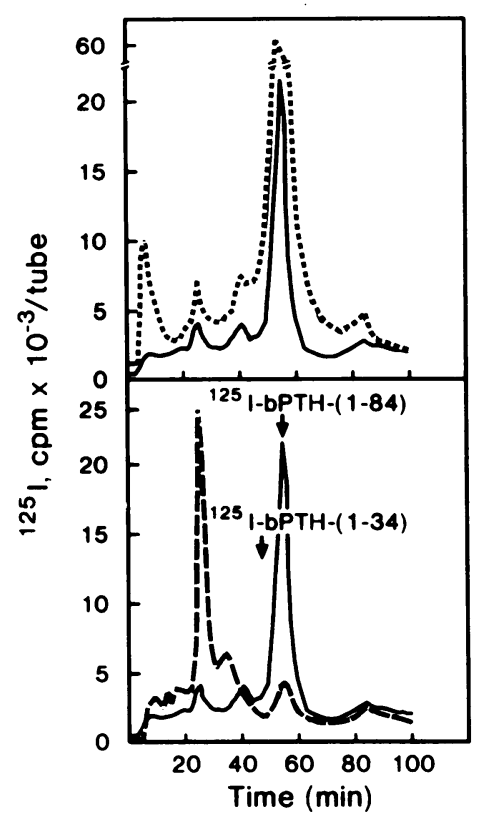

Figure 7. Reverse-phase HPLC of radioiodinated PTH, and its analogs and fragments. Upper panel, monoiodinated ${ }^{125} \mathrm{I}-\mathrm{bPTH}$ (1-84) before (-- -) and after (-) perfusion through the rat hindquarters. Lower panel, ${ }^{125}$ IbPTH-(1-84) after perfusion through rat hindquarters $(-)$, and after incubation with cathepsin D (- - -). Elution volume of radioiodinated bPTH-(1-34) is also shown by the arrow.

Effects of the two PTH peptides on cAMP release were indistinguishable over the dose range 0.1-2 nmol. However, increasing doses of bPTH-(1-34) beyond this range continued to stimulate cAMP release, finally reaching a plateau at $11.6 \mathrm{nmol}$, while the responses to doses of bPTH-(1-84) beyond this range plateaued or declined. We have no ready explanation for this phenomenon, but it strongly suggests that potency comparisons of PTH and its analogs must encompass full dose-response curves, to obtain complete information. These findings also demonstrate that potency comparisons of PTH preparations made in kidney may not accurately reflect their relative potencies in bone. The synthetic bPTH-(1-34) was 2.8-fold more potent than the native bPTH-(1-84) when bioassayed in the canine renal plasma membrane adenylate cyclase system, while these hormone preparations were essentially equipotent in our perfused bone system. These differences in potency estimates strongly suggest that careful consideration be given to the choice of organ system and species used to test the efficacy of PTH analogs.

Another important finding in these studies was that BGP was released continuously from perfused rat bone; moreover, this release acutely responded to PTH. Administration of bPTH$(1-84)$ and bPTH-(1-34) suppressed BGP release to below that of vehicle-perfused rats. The difference in the degree of suppression observed between the two hormonal treatments suggests that the magnitude of BGP suppression by PTH may be dosedependent in perfused whole bone, as it was in bone cells (36).

Beresford et al. (36) reported that cultured osteoblast-like human bone cells stimulated with 1,25 dihydroxyvitamin $D_{3}$ $\left[1,25(\mathrm{OH})_{2} \mathrm{D}_{3}\right]$ released BGP. When these cells were incubated with $1,25(\mathrm{OH})_{2} \mathrm{D}_{3}$ and $\mathrm{PTH}$, there was a dose-dependent decrease in BGP release over a 48-h period. The reduction in BGP release was very slow and highly dependent upon stimulation with $1,25(\mathrm{OH})_{2} \mathrm{D}_{3}$ for initial release of BGP. By contrast, in the present study, perfused bone responded within minutes to a single dose of PTH by markedly reduced BGP release. PTH action may suppress BGP release by altering the rate of BGP synthesis or degradation, presumably by osteoblasts (37). The rapidity of 
this response supports the proposed function of BGP as an informational protein responsible for regulation of cellular activities involved in bone turnover (38). BGP release from vehicleperfused preparations also declined substantially with time, for unknown reasons; because of this, we believe our findings with respect to PTH inhibition of BGP release should be interpreted with caution.

In summary, the isolated perfused rat hindquarter system is a very useful model for the study of acute PTH actions on mature mammalian bone; we have only begun to explore its potential. The preparations also released cAMP in response to salmon calcitonin (unpublished results), but specificity of the response to bone has not been established. Both synthetic bPTH-(1-34) and native $\mathrm{BPTH}-(1-84)$ produced dose-dependent increases of cAMP release over a wide range of hormone doses. Mature murine bone clearly did not require extraskeletal cleavage of intact PTH to an $\mathrm{NH}_{2}$-terminal fragment for biological activity, and it could not cleave the intact hormone under the conditions of our perfusion system. BGP was also released from perfused rat hindquarters, and the administration of PTH produced a significant decline in BGP release. These findings suggest that PTH may acutely suppress the release of BGP from osteoblasts.

\section{Acknowledgments}

We thank Marylee E. Campion for preparation of the manuscript.

This work was supported in part by a grant from the National Institutes of Health (AM19607), and by a grant from the Medical Research Council of Canada (MA4515).

\section{References}

1. Parsons, J. A., and C. J. Robinson. 1968. A rapid induced hypercalcemic action of parathyroid hormone demonstrated in isolated bloodperfused bone. In Parathyroid Hormone and Thyrocalcitonin (calcitonin). R. V. Talmage and L. F. Belanger, editors. Excerpta Medica, Amsterdam. 329-331.

2. Martin, K. J., K. A. Hruska, J. J. Freitag, S. Klahr, and E. Slatopolsky. 1979. The peripheral metabolism of parathyroid hormone. $N$. Engl. J. Med. 301:1092-1098.

3. Canterbury, J. M., L. A. Bricker, G. S. Levey, P. L. Kozlovskis, E. Ruiz, J. E. Zull, and E. Reiss. 1975. Metabolism of bovine parathyroid hormone. Immunological and biological characteristics of fragments generated by liver perfusion. J. Clin. Invest. 55:1245-1253.

4. Martin, K., K. Hruska, A. Greenwalt, S. Klahr, and E. Slatopolsky. 1976. Selective uptake of intact parathyroid hormone by the liver. Differences between hepatic and renal uptake. J. Clin. Invest. 58:781-788.

5. Hruska, K. A., A. Korkor, K. Martin, and E. Slatopolsky. 1981. Peripheral metabolism of intact parathyroid hormone. Role of liver and kidney and the effect of chronic renal failure. J. Clin. Invest. 67:885892.

6. Martin, K. J., J. J. Freitag, M. B. Conrades, K. A. Hruska, S. Klahr, and E. Slatopolsky. 1978. Selective uptake of the synthetic amino terminal fragment of bovine parathyroid hormone by isolated perfused bone. J. Clin. Invest. 62:256-261.

7. Goltzman, D. 1978. Examination of the requirement for metabolism of parathyroid hormone in skeletal tissue before biological action. Endocrinology. 102:1555-1562.

8. Crowell, J. A., C. W. Cooper, S. U. Toverud, and A. Boass. 1984. Effects of vitamin D and parathyroid hormone on cyclic AMP production by bone cells isolated from rat calvaria. Calcif. Tissue Int. 36:320-326.

9. Freitag, J. J., K. J. Martin, M. B. Conrades, and E. Slatopolsky. 1979. Metabolism of parathyroid hormone by fetal rat calvaria. Endocrinology. 104:510-516.
10. Silve, C. M., G. T. Hradek, A. L. Jones, and C. D. Arnaud. 1982. Parathyroid hormone receptor in intact embryonic chicken bone: characterization and cellular localization. J. Cell. Biol. 94:379-386.

11. Pliam, N. B., K. O. Nyiredy, and C. D. Arnaud. 1982. Parathyroid hormone receptors in avian bone cells. Proc. Natl. Acad. Sci. USA. 79: 2061-2063.

12. Bliziotes, M. M., S. B. Lewis, and J. H. Licht. 1982. Dose-related influence of indomethacin on parathyroid hormone-stimulated adenosine 3'5'-monophosphate relèase from the perfused rat hindlimb. Endocrinology. 111:1657-1662.

13. Ruderman, N. B., C. R. S. Houghton, and R. Hems. 1976. Evaluation of the isolated perfused rat hindquarter for the study of muscle metabolism. Biochem. J. 124:639-651.

14. Schultz, T. A., S. B. Lewis, D. R. Westbie, J. D. Wallin, and J. E. Gerich. 1977. Glucose delivery: a modulator of glucose uptake in contracting skeletal muscle. Am. J. Physiol. 233:E514-E518.

15. Hamilton, R. L., M. N. Berry, M. C. Williams, and E. M. Severinghaus. 1974. A simple and inexpensive membrane "lung" for small organ perfusion. J. Lipid Res. 15:182-186.

16. Steiner, A. L., A. S. Pagliara, L. R. Chase, and D. M. Kipnis. 1972. Radioimmunoassay for cyclic nucleotides. II. Adenosine $3^{\prime}, 5^{\prime}$ monophosphate and guanosine $3^{\prime}, 5^{\prime}$-monophosphate in mammalian tissues and body fluids. J. Biol. Chem. 247:1114-1120.

17. Steiner, A. L., C. W. Parker, and D. M. Kipnis. 1972. Radioimmunoassay for cyclic nucleotides. I. Preparation of antibodies and iodinated cyclic nucleotides. J. Biol. Chem. 247:1106-1103.

18. Wray, H. L., and A. D. Glinos. 1978. Cyclic nucleotides and growth regulation in suspension cultures of mammalian cells. $\mathrm{Am}$. J. Physiol. 234:C131-C138.

19. Price, P. A., and S. K. Nishimoto. 1980. Radioimmunoassay for the vitamin K-dependent protein of bone and its discovery in plasma. Proc. Natl. Acad. Sci. USA. 77:2234-2238.

20. Nissenson, R. A., S. R. Abbott, A. P. Teitelbaum, O. H. Clark, and C. D. Arnaud. 1981. Endogenous biologically-active human parathyroid hormone: measurement by guanyl nucleotide-amplified renal adenylate cyclase assay. J. Clin. Endocrinol. Metab. 52:840-846.

21. Rosenberg, R. A., T. M. Murray, S. A. Muzzafar, D. Jez, and J. M. Heersche. 1983. Preparation and properties of biologically active radioiodinated parathyroid hormone. Anal. Biochem. 128:331-341.

22. Nissenson, R. A., and C. D. Arnaud. 1979. Properties of the parathyroid hormone receptor adenylate cyclase system in chicken renal plasma membranes. J. Biol. Chem. 254:1469-1475.

23. Rizzoli, R. E., M. Somerman, T. M. Murray, and G. D. Aurbach. 1983. Binding of radioiodinated parathyroid hormone to cloned bone cells. Endocrinology. 113:1832-1838.

24. Bennett, H. P. J., S. Solomon, and D. Goltzman. 1981. Isolation and analysis of human parathyrin in parathyroid tissue and plasma: use of reversed-phase liquid chromatography. Biochem. J. 197:391-400.

25. Hamilton, J. W., R. L. Jilka, and R. R. MacGregor. 1983. Cleavage of parathyroid hormone to the 1-34 and 35-84 fragments by cathepsin D-like activity in bovine parathyroid gland extracts. Endocrinology. 113: 285-292.

26. Pilliai, S., R. Botti, Jr., and J. E. Zull. 1983. ATP activation of parathyroid hormone cleavage catalyzed by cathepsin $\mathrm{D}$ from bovine kidney. J. Biol. Chem. 258:9724-9728.

27. Garber, A. J. 1983. Effects of parathyroid hormone on skeletal muscle protein and amino acid metabolism in the rat. J. Clin. Invest. 71:1806-1821.

28. Pang, P. K. T., T. E. Tenner, J. A. Yee, M. C. Yang, and H. F. Jansen. 1980. Hypotensive action of parathyroid hormone preparations on rats and dogs. Proc. Natl. Acad. Sci. USA. 77:675-678.

29. Ellison, D. H., and D. A. McCarron. 1984. Structural prerequisites for the hypotensive action of parathyroid hormone. Am. J. Physiol. 246: F551-F556.

30. Helwig, J. J., R. Scheiffer, C. Judes, and A. Gacrard. 1984. Dis- 
tribution of parathyroid hormone-sensitive adenylate cyclase in isolated rabbit renal cortex microvessels and glomeruli. Life Sci. 35:2649-2657.

31. Thajchayapong, P., S. F. Queener, R. McClintock, D. O. Allen, and N. H. Bell. 1976. Demonstration that cyclic adenosine 3',5'-monophosphate mediates the lipolytic action of parathyroid hormone. Horm. Metab. Res. 8:190-195.

32. Smith, D. M., and C. C. Johnston, Jr. 1975. Cyclic 3',5'-monophosphate levels in separated bone cells. Endocrinology. 96:1261-1269.

33. Price, P. A., M. K. Williamson, and J. W. Lothringer. 1981. Origin of the vitamin K-dependent bone protein found in plasma and its clearance by kidney and bone. J. Biol. Chem. 256:12760-12766.

34. Kather, H., and B. Simon. 1977. Adenylate cyclase of human fat cell ghosts. J. Clin. Invest. 59:730-733.

35. Herrmann-Erlee, M. P. M., P. J. Nijweide, J. M. van der Meer, and M. A. C. Ooms. 1983. Action of bPTH and bPTH fragments on embryonic bone in vitro: dissociation of the cyclic AMP and bone resorbing response. Calcif. Tissue Int. 35:70-77.

36. Beresford, J. N., J. A. Gallagher, J. W. Posen, and R. G. G. Russell. 1984. Production of osteocalcin by human bone cells in vitro. Effects of $1,25(\mathrm{OH})_{2} \mathrm{D}_{3}, 24,25(\mathrm{OH})_{2} \mathrm{D}_{3}$, parathyroid hormone, and glucocorticoids. Metab. Bone Dis. \& Relat. Res. 5:229-234.

37. Nishimoto, S. K., and P. A. Price. 1979. Proof that the $\gamma$-carboxyglutamic acid-containing bone protein is synthesized in calf bone. J. Biol. Chem. 254:437-441.

38. Price, P. A., and S. A. Baukol. 1980. 1,25-dihydroxyvitamin $D_{3}$ increases synthesis of vitamin $\mathrm{K}$-dependent bone protein by osteosarcoma cells. J. Biol. Chem. 255:11660-11663. 